\title{
Interdecadal Climate Variations Controlling the Water Level of Lake Qinghai over the Tibetan Plateau ${ }^{\mathscr{O}}$
}

\author{
LIN ZHAO \\ Key Laboratory of Land Surface Process and Climate Change in Cold and Arid Regions, Northwest Institute of \\ Eco-Environment and Resources, Chinese Academy of Sciences, Lanzhou, Gansu, China, \\ and Department of Plants, Soils, and Climate, Utah State University, Logan, Utah \\ S.-Y. SimON WANG AND JonATHAN MEYeR \\ Utah Climate Center, and Department of Plants, Soils, and Climate, Utah State University, Logan, Utah
}

(Manuscript received 18 April 2017, in final form 31 July 2017)

\begin{abstract}
Using observed and reanalysis data, the pronounced interdecadal variations of Lake Qinghai (LQH) water levels and associated climate factors were diagnosed. From the 1960s to the early 2000s, the water level of LQH in the Tibetan Plateau has experienced a continual decline of $3 \mathrm{~m}$ but has since increased considerably. A water budget analysis of the LQH watershed suggested that the water vapor flux divergence $\nabla \cdot \mathbf{Q}$ is the dominant atmospheric process modulating precipitation and subsequently the lake volume change $\Delta V$. The marked interdecadal variability in $\Delta V$ and $\nabla \cdot \mathbf{Q}$ was found to be related to the North Pacific (NP) and Pacific decadal oscillation (PDO) modes during the cold season (November-March). Through empirical orthogonal function (EOF) and regression analyses, the water vapor sink over the LQH watershed also responds significantly to the summer Eurasian wave train modulated by the low-frequency variability associated with the cold season NP and PDO modes. Removal of these variability modes (NP, PDO, and the Eurasian wave train) led to a residual uptrend in the hydrological variables of $\Delta V, \nabla \cdot \mathbf{Q}$, and precipitation, corresponding to the net water level increase. Attribution analysis using the Coupled Model Intercomparison Project phase 5 (CMIP5) single-forcing experiments shows that the simulations driven by greenhouse gas forcing produced a significant increase in the LQH precipitation, while anthropogenic aerosols generated a minor wetting trend as well.
\end{abstract}

\section{Introduction}

Lake Qinghai $(\mathrm{LQH})$ is the largest inland lake in China located in the northwest margin of the Tibetan Plateau (Fig. 1a). LQH is a terminal lake, slightly saline without surface water outflow, and it occupies an area of $4318 \mathrm{~km}^{2}$ with an altitude over $3000 \mathrm{~m}$ (Fig. 1b). At this high elevation, LQH experiences frozen periods lasting from late December to the beginning of April (Che et al. 2009). Inflow to the lake is provided by more than 50 intermittent rivers and streams (Fig. 1b; Jin et al. 2010). From the 1960s to the early 2000s, the water level of LQH has experienced substantial interannual and interdecadal variability while exhibiting a continual decline of $3 \mathrm{~m}$

Supplemental information related to this paper is available at the Journals Online website: https://doi.org/10.1175/JHM-D-17-0071.s1.

Corresponding author: Lin Zhao, zhaolin_110@lzb.ac.cn
(Fig. 1c). Such considerable losses in the water level have resulted in serious environmental problems, such as desertification in the beach area, loss of grazing grassland around the lake, and deterioration of the water quality (Qin and Huang 1998). The atmospheric and hydrological cycles of the Tibetan Plateau have experienced pronounced effects of climate changes (Yang et al. 2014). The reported LQH water level decline has been associated with a transition from a wet climate to a drier climate (Li et al. 2005, 2007; Xu et al. 2007).

Notably, more recent data after 2004 indicates that the LQH water level has been increasing for over a decade (Fig. 1c); this is also evident in the water level tendency (Fig. 1d). This observation echoes others that reported that many lakes in the interior Tibetan Plateau have shrunk during the period of 1970-90, but then expanded and deepened significantly since the late 2000s (Song et al. 2013; Zhang et al. 2014), contradicting the earlier claim of a drying trend. As a terminal lake, the water 

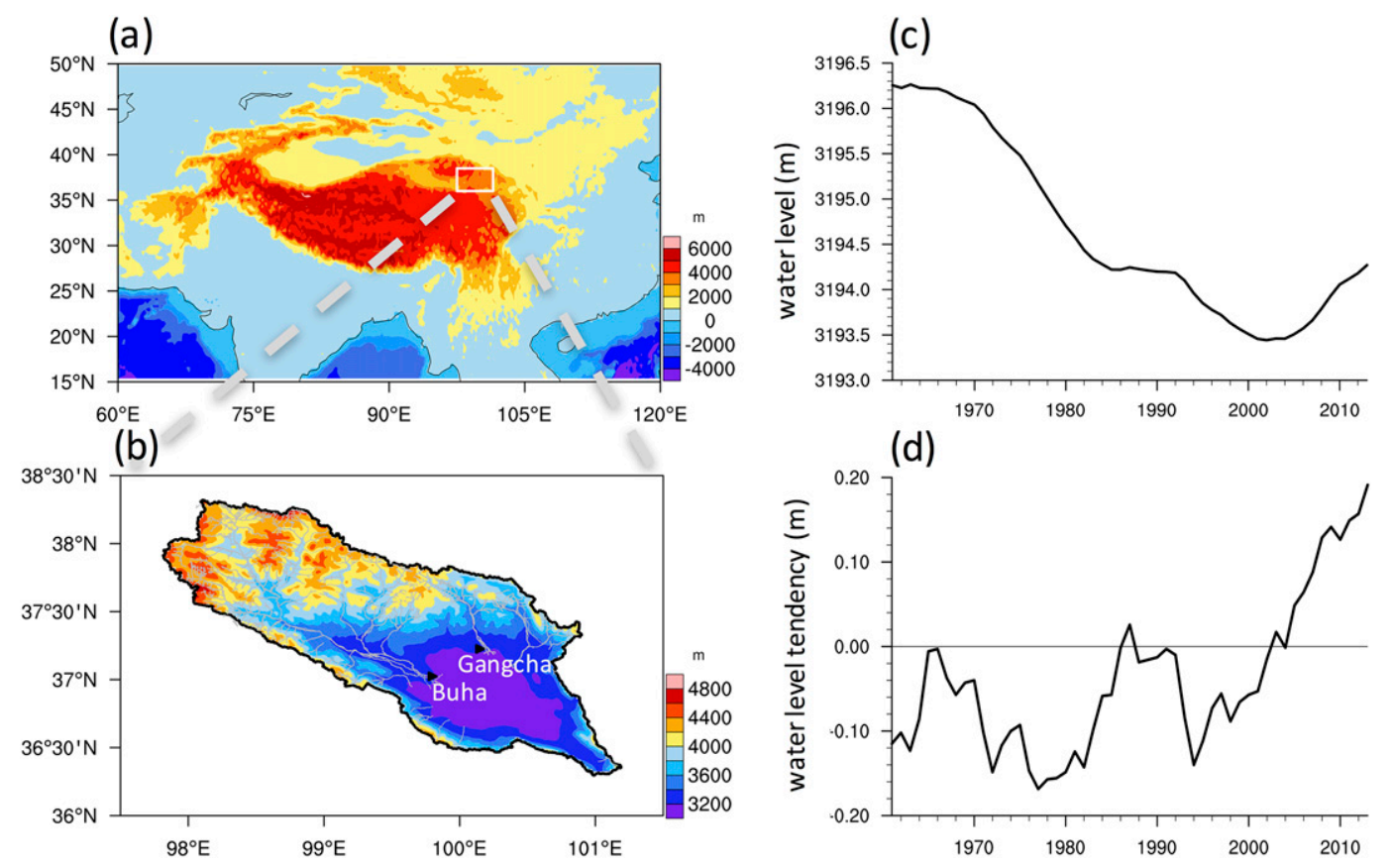

FIG. 1. Elevation (m MSL) of the (a) Tibetan Plateau and (b) LQH watershed and time series of (c) LQH water level $(\mathrm{m})$ and $(\mathrm{d})$ water level tendency $(\mathrm{m})$. Gray lines in (b) indicate runoff; black triangles in (b) indicate the Buha and Gangcha stations for runoff.

level responds primarily to atmospheric processes controlling regional precipitation and runoff. Increased precipitation (Lei et al. 2014; Song et al. 2014), accelerated glacier/snow melting (Lei et al. 2012; Zhang et al. 2011), and permafrost degradation ( $\mathrm{Li}$ et al. 2014; Liu et al. 2010) are thought to be responsible for the recent water level increasing in those inland lakes over the Tibetan Plateau. With only a minor influence from human activities, LQH's water level variation is an important indicator of regional climate and environmental changes.

One aspect affecting LQH that has not been adequately addressed is the influence of certain atmospheric stationary wave patterns characterizing the midlatitude climate regime, such as the so-called Silk Road (SR) pattern (or Eurasian wave train), the circumglobal teleconnection (CGT) pattern, and the Europe-China (EC) pattern (Chen and Huang 2012; Ding and Wang 2005, 2007; Enomoto et al. 2003). These wave patterns are the zonally asymmetric features of the time-averaged atmospheric circulation anomalies, which may be persistently present on a timescale from a month up to a season. Besides these atmospheric teleconnection (or Rossby wave) patterns, the fluctuations in the westerly jet stream, East Asian monsoon, and Indian summer monsoon systems can modulate the LQH watershed as well (Sha et al. 2015; Yao et al. 2012). Other studies have connected the aforementioned Rossby wave patterns with variations of the Indian summer monsoon
(Ding and Wang 2007), eastern Tibetan Plateau precipitation (Hu et al. 2016), and northwest China summer precipitation (Chen and Huang 2012). Specifically, Chen and Huang (2012) suggested that tropical heating anomalies located over the north Indian Ocean and equatorial central Pacific, Indonesia, and tropical Atlantic are potential forcing sources of those midlatitude Rossby wave patterns across Eurasia and the Tibetan Plateau.

Hawkins and Sutton (2009) suggested that the uncertainty in climate change due to natural variability is greater than that in anthropogenic forcing, at least for the next $10-30$ years. This implies that naturally driven interdecadal variability may be of critical importance to the climate prediction of LQH. On interdecadal time scales, the winter climate fluctuations in the Northern Hemisphere are pronouncedly reflected by two benchmark indices over the Pacific Ocean: the North Pacific (NP) mode (Trenberth and Hurrell 1994) and the Pacific decadal oscillation (PDO) of Mantua et al. (1997). The former is defined by sea level pressure (SLP) anomalies averaged between $30^{\circ}$ and $65^{\circ} \mathrm{N}$ over the North Pacific, while the latter is defined as the leading principal component of sea surface temperature (SST) anomalies between $20^{\circ}$ and $70^{\circ} \mathrm{N}$. These two modes are, however, not independent of each other. Throughout the cold season, NP variability typically leads the PDO for certain years (Newman et al. 2016). Thus, the extent to which LQH water level 
variability may be linked to global-scale climate modes such as the NP and PDO has not been explored.

In this study, we aimed to diagnose the predominant low-frequency (i.e., interdecadal) variability of the water level changes of $\mathrm{LQH}$. We examined the water budget and explored the dynamic mechanism of atmospheric processes that are related to the water level changes. The effect of global warming on water level changes is also discussed. The paper is organized as follows. Section 2 describes the data and methods used in this study. The analysis results are presented in section 3. Section 4 gives a discussion and conclusions.

\section{Data and methods}

\section{a. Data sources}

The annual mean LQH water level data were obtained from 1961 to 2009 at the Xiashe station; it was extended to 2013 with remote sensing data (Crétaux et al. 2011). The water level of $\mathrm{LQH}$ was converted to water volume using the elevation-volume relationships developed by Zhang et al. (2013). Runoff data for LQH from 1961 to 2009 are measured by the Buha and Gangcha stations (Fig. 1b). Runoff at these two stations contributes to $64 \%$ of the total streamflow into the lake (Qing and Shi 1992). Precipitation was derived from a gridded dataset with a high spatial resolution of $0.25^{\circ} \times 0.25^{\circ}$ constructed from over 2400 observing stations in China (Wu and Gao 2013). As shown in Fig. 1b, the term LQH watershed was defined as the domain of $36.00^{\circ}-38.50^{\circ} \mathrm{N}, 97.50^{\circ}-101.50^{\circ} \mathrm{E}$.

Isobaric variables of horizontal winds, humidity, temperature, and surface pressure data were obtained from four reanalysis datasets, including the National Centers for Environmental Prediction-Department of Energy (NCEP-DOE) Global Reanalysis 2 (NCEP-2) at a $2.5^{\circ}$ resolution from 1979 onward (Kanamitsu et al. 2002), the Japanese 55-yr Reanalysis (JRA-55; Kobayashi et al. 2015 ) at a $1.25^{\circ}$ resolution from 1961 to 2013 , the $40-\mathrm{yr}$ European Centre for Medium-Range Weather Forecasts (ECMWF) Re-Analysis (ERA-40) at a $1^{\circ}$ resolution from 1961 to 1978 (Uppala et al. 2005), and the ECMWF interim reanalysis (ERA-Interim) at a $1^{\circ}$ resolution from 1979 to 2013 (Dee et al. 2011). Using bilinear interpolation and conservative regridding, these four reanalysis datasets were regridded to a uniform $1.25^{\circ}$ resolution data to produce an ensemble reanalysis. The ensemble reanalysis of 1961-78 used JRA-55 and ERA-40 while 1979-2013 used the average of JRA-55, ERA-Interim, and NCEP-2.

The correspondence of LQH's volume changes to seasonal precipitation occurs most significantly in the cold season; this was obtained by the cross correlation calculated between the unfiltered data of annual precipitation and lake volume change $\Delta V$ averaged over 12 months with a 1-month time lag, from month -24 (previous two calendar years) to month 0 (same calendar year; see Fig. S1 in the online supplement). The highest correlation $(>0.6)$ of precipitation occurs from around the lag -5 month through the lag -15 month, covering both winter and summer. Regardless, we focused on the cold season of November-March (NDJFM) for some circulation analysis such as NP and PDO, which are known to prevail in winter. The NDJFM season's NP and PDO indices were obtained from NOAA (https://www.esrl. noaa.gov/psd/data/climateindices/list/).

Large-scale planetary waves are undulations associated with each hemisphere's polar jet stream and develop in response to the fluid dynamics of a rotating sphere. More commonly referred to as Rossby waves, these features propagate midlatitude cyclones and therefore play an integral role in modulating regional climate. To analyze the propagation features of a stationary Rossby wave in the extratropical region, we calculated the wave activity flux (WAF) by following the derivation of Takaya and Nakamura (2001), which is based on the conservation of wave activity pseudomomentum. The horizontal components of the phase-independent WAF can be given by

$$
\mathrm{WAF}=\frac{1}{2|\overline{\mathbf{U}}|}\left[\begin{array}{l}
\bar{u}\left(\psi_{x}^{\prime 2}-\psi^{\prime} \psi_{x x}^{\prime}\right)+\bar{v}\left(\psi_{x}^{\prime} \psi_{y}^{\prime}-\psi^{\prime} \psi_{x y}^{\prime}\right) \\
\bar{u}\left(\psi_{x}^{\prime} \psi_{y}^{\prime}-\psi^{\prime} \psi_{x y}^{\prime}\right)+\bar{v}\left(\psi_{y}^{\prime 2}-\psi^{\prime} \psi_{y y}^{\prime}\right)
\end{array}\right]
$$

where $u$ is the zonal wind velocity, $v$ is the meridional wind velocity, and $\psi$ is the streamfunction. Here, $\mathbf{U}=(u, v)$ represents the mean zonal and meridional winds. The overbars represent the basic states and primes represent perturbations. In this study, we used the 53-yr (1961-2013) summer climatology as the basic state and seasonal anomalies derived from the basic states as the perturbations.

For the attribution analysis of external climate forcing, we also analyzed precipitation outputs of 10 models from phase 5 of the Coupled Model Intercomparison Project (CMIP5) historical single forcing experiments, which were driven by 1 ) only greenhouse gas forcing (GHG), 2) only aerosol forcing (AERO), 3) only natural forcing including volcanic and solar forcing (NAT), and 4) all of the forcings combined (ALL) (Taylor et al. 2012). These experiments were initialized from a long, stable preindustrial (1850) control run up to 2005. The specifics of these models are described in Table 1.

\section{b. Water budget equation}

The time-mean hydrological cycle of the LQH watershed can be represented in terms of the atmospheric water vapor budget: 
TABLE 1. CMIP5 models used in this study.

\begin{tabular}{|c|c|c|c|}
\hline Acronym & Model name & Organization, country & $\begin{array}{l}\text { Ensemble } \\
\text { member size }\end{array}$ \\
\hline CanESM2 & $\begin{array}{l}\text { Second Generation Canadian Earth } \\
\text { System Model }\end{array}$ & $\begin{array}{l}\text { Canadian Centre for Climate Modelling and } \\
\text { Analysis, Canada }\end{array}$ & 5 \\
\hline CCSM4 & $\begin{array}{l}\text { Community Climate System Model, } \\
\text { version } 4\end{array}$ & $\begin{array}{l}\text { National Center for Atmospheric Research, } \\
\text { United States }\end{array}$ & 3 \\
\hline CNRM-CM5 & $\begin{array}{l}\text { Centre National de Recherches } \\
\text { Météorologiques Coupled Global } \\
\text { Climate Model, version } 5\end{array}$ & $\begin{array}{l}\text { Centre National de Recherches Météorologiques/ } \\
\text { Centre Européen de Recherche et de Formation } \\
\text { Avancée en Calcul Scientifique, France }\end{array}$ & 6 \\
\hline GFDL CM3 & $\begin{array}{l}\text { Geophysical Fluid Dynamics Laboratory } \\
\text { Climate Model, version } 3\end{array}$ & $\begin{array}{l}\text { National Oceanic and Atmospheric Administration/ } \\
\text { Geophysical Fluid Dynamics Laboratory, } \\
\text { United States }\end{array}$ & 3 \\
\hline GFDL-ESM2M & $\begin{array}{l}\text { Geophysical Fluid Dynamics Laboratory } \\
\text { Earth System Model with MOM, } \\
\text { version } 4 \text { component }\end{array}$ & $\begin{array}{l}\text { National Oceanic and Atmospheric Administration/ } \\
\text { Geophysical Fluid Dynamics Laboratory, } \\
\text { United States }\end{array}$ & 1 \\
\hline CSIRO Mk3.6.0 & $\begin{array}{l}\text { Commonwealth Scientific and Industrial } \\
\text { Research Organization Mark 3.6.0 }\end{array}$ & $\begin{array}{l}\text { Commonwealth Scientific and Industrial Research } \\
\text { Organization/Queensland Climate Change } \\
\text { Centre of Excellence, Australia }\end{array}$ & 4 \\
\hline FGOALS & $\begin{array}{l}\text { Flexible Global Ocean-Atmosphere-Land } \\
\text { System Model }\end{array}$ & $\begin{array}{l}\text { Institute of Atmospheric Physics, Chinese Academy } \\
\text { of Sciences, China }\end{array}$ & 1 \\
\hline GISS-E2 & $\begin{array}{l}\text { Goddard Institute for Space Studies } \\
\text { Model E2 }\end{array}$ & $\begin{array}{l}\text { National Aeronautics and Space Administration } \\
\text { Goddard Institute for Space Studies, } \\
\text { United States }\end{array}$ & 3 \\
\hline IPSL-CM5 & $\begin{array}{l}\text { L'Institut Pierre-Simon Laplace Coupled } \\
\text { Model, version } 5\end{array}$ & L'Institut Pierre-Simon Laplace, France & 3 \\
\hline NorESM1-M & $\begin{array}{l}\text { Norwegian Earth System Model, } \\
\text { version } 1 \text { (intermediate resolution) }\end{array}$ & Norwegian Climate Centre, Norway & 1 \\
\hline
\end{tabular}

$$
\partial W / \partial t+\nabla \cdot \mathbf{Q}=E-P
$$

where $W, \mathbf{Q}, E$, and $P$ are precipitable water, vertically integrated water vapor flux (i.e., from the surface to $200 \mathrm{hPa}$ ), evaporation, and precipitation, respectively. Based on the generalized water balance for a closedbasin lake, the water volume changes $\Delta V$ can be expressed as

$$
\Delta V=P+R-E-D,
$$

where $R$ is the runoff coming from the surrounding watershed, and $D$ is the discharge from the basin. At high altitudes within the Tibetan Plateau, $D$ for human activity such as irrigation is insignificant and can be negligible in the LQH watershed. Following Shanahan et al. (2007) and Wang et al. (2010), the connection between the hydrology and atmospheric processes can be combined and rewritten as

$$
\partial W / \partial t+\nabla \cdot \mathbf{Q}=R-\Delta V .
$$

It is noted that the atmospheric and hydrological variables in the following text are domain averaged over the LQH watershed as mentioned above. Also, all units of variables are unified to centimeters per month.

\section{Results}

\section{a. Water budget analysis}

\section{1) LQH'S VOLUME CHANGES AND INCOMING RUNOFF}

LQH's volume changes $\Delta V$ and incoming runoff $R$ represent the terrestrial branch of the water budget in Eq. (4). The noted interdecadal variability can be isolated by applying a 7-yr low-pass filter to each term in Eq. (4). Figure 2 a shows that the interdecadal variability of the observed annual volume changes at LQH (flipped, $-\Delta V$ ) is similar to LQH's water level changes (Fig. 1d) from 1961 to 1994. After that, LQH's volume changes show a continuous increase. The time series of observed $R$ are coherent with $-\Delta V$, despite a smaller magnitude (Figs. 2a,b), implying that $R$ from the LQH watershed is an important source for $\Delta V$. To address the uncertainty of the water budget analysis, a different computation of $-\Delta V$ was derived from the residual term based on Eq. (4). As can be seen in Fig. 2b, the observed (gray line) and residual (black line) $-\Delta V$ do not fit well before 1990 but share a marked resemblance afterward.

To examine the interdecadal variability in the LQH water level, power spectral analyses of annual $\Delta V$, water level $H$, and NDJFM NP and PDO were conducted by 

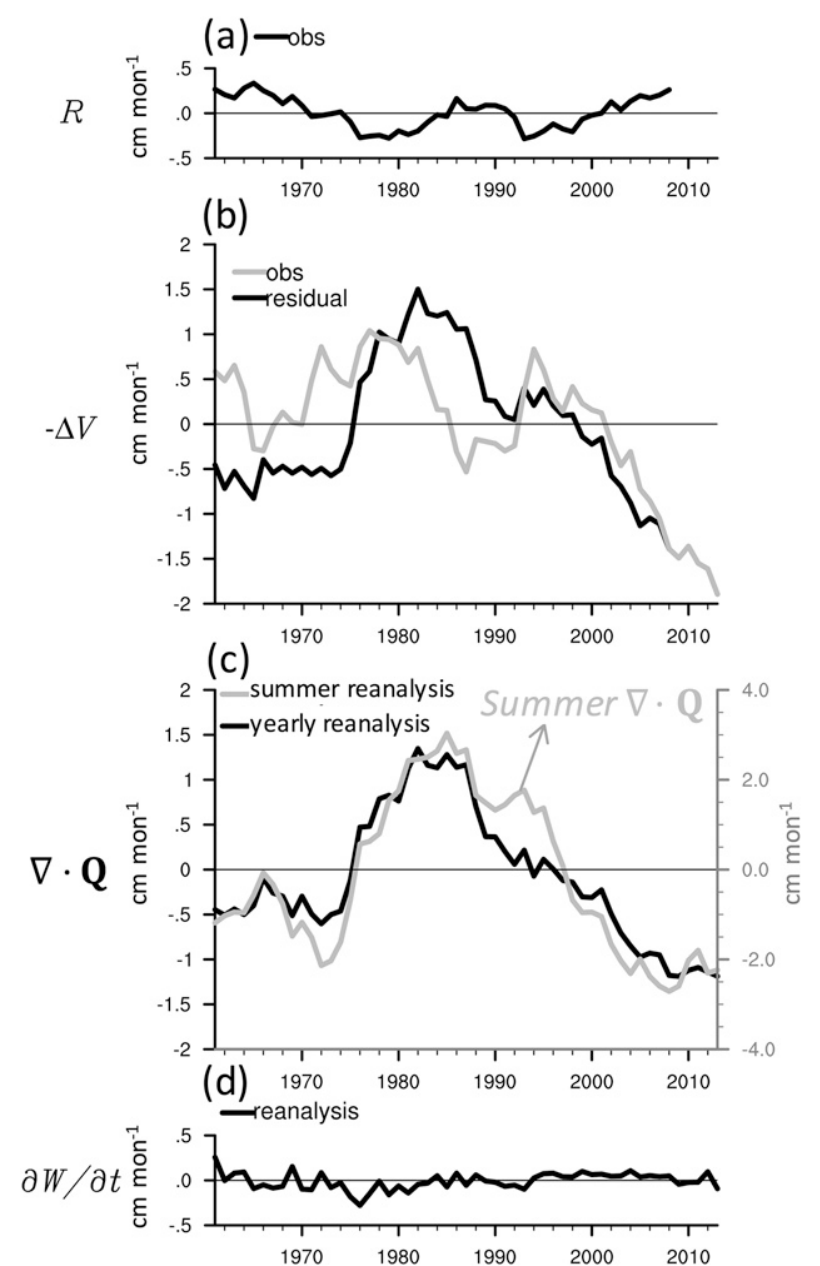

FIG. 2. Time series of the monthly (a) runoff anomalies $R$, (b) LQH $\Delta V$ (flipped), (c) water vapor flux divergence anomalies $\nabla \cdot \mathbf{Q}$, and (d) the changing rate of precipitable water anomalies $\partial W / \partial t$ with a 7-yr low-pass filter (all units are $\mathrm{cm} \mathrm{month}{ }^{-1}$ ). Gray lines in (b) and (c) indicate observed $R$ and summer $\nabla \cdot \mathbf{Q}$, respectively.

performing the temporal to frequency transformation via the fast Fourier transform (Cochran et al. 1967). Here, we used the unfiltered data with the linear trend removed before the spectral analyses. Both $\Delta V$ and $H$ show significant interannual signals within 3-8 years, with a noticeable 12-25-yr mode (Figs. 3a,b) that is similar to NP and PDO (Figs. 3c,d). To further understand the association of $\Delta V$ with the NP and PDO, their spectral coherence analysis was conducted with the periodograms smoothed with the Daniell filter (Daniell 1946) (here, the Daniell filter differs from the common moving average in that the first and last weights are halved to reduce what is known as the leakage effect). As shown in Figs. 3e and 3f, a high degree of coherency between NP and $\Delta V$ is revealed in both interannual (3.5 years) and interdecadal 16-yr frequencies, but with a $40^{\circ}$ and $60^{\circ}$ phase difference, respectively. Significant 16 -yr signals are also found between the PDO and yearly $\Delta V$, with a nearly $90^{\circ}$ phase difference. Overall, the interdecadal variation of $\mathrm{LQH}$ volume changes is statistically linked to the Pacific Ocean climate variability in terms of NP and PDO.

\section{2) LOCAL MOISTURE CHANGE}

The aforementioned LQH volume changes and runoff represent the terrestrial branch of Eq. (4), which should be balanced by water vapor in the atmosphere. Next, we explored the moisture changes in the atmosphere represented by the rate of change of precipitable water $\partial W / \partial t$. For the period of 1961-2013, $\partial W / \partial t$ was derived from the ensemble reanalysis and subjected to the same 7-yr low-pass filter applied to the $\Delta V$ analysis discussed in section 3a. As shown in Fig. 2d, $\partial W / \partial t$ over the LQH watershed only fluctuates between -0.5 and $0.5 \mathrm{~cm}$ month $^{-1}$. It is known that $\partial W / \partial t$ is generally small compared with the other terms in the water budget (Peixoto and Oort 1992), except in the case of severe storms and for short intervals of time.

\section{3) REgIONAL-SCALE WATER VAPOR CONVERGENCE}

With the application of the 7-yr low-pass filtering on the ensemble reanalysis, we examined the source controlling the regional convergence of water vapor fluxes represented by $\nabla \cdot \mathbf{Q}$. Figure 2c exhibits a substantial decadal variation along with an increasing trend before the mid1980s, which has since been replaced by a decreasing trend. The variation of summer (i.e., JJA) $\nabla \cdot \mathbf{Q}$ is similar to the yearly one, but almost doubled in the range between maximum and minimum values; this difference will be discussed in the ensuing analysis. Overall, the aforementioned water budget analysis indicates that the LQH water level changes are highly related to the atmospheric processes in the form of $\nabla \cdot \mathbf{Q}$, especially during the recent three decades. The possible reason for the inconsistency between $-\Delta V$ and $\nabla \cdot \mathbf{Q}$ in the earlier period may be related to the lack of satellite data before the 1980s, which is an important source of information assimilated within the reanalysis data.

\section{b. The teleconnection patterns}

Given the aforementioned water budget results, we were led to the question concerning how the atmospheric circulation modulates the hydrological cycle of the LQH watershed. To answer this question, the spatial and temporal features of atmospheric circulation variations were examined. Climatologically, $\mathrm{LQH}$ receives more than $60 \%$ of its total precipitation during the summer (Shi et al. 2005). Therefore, by applying the 
(a) $\Delta V$

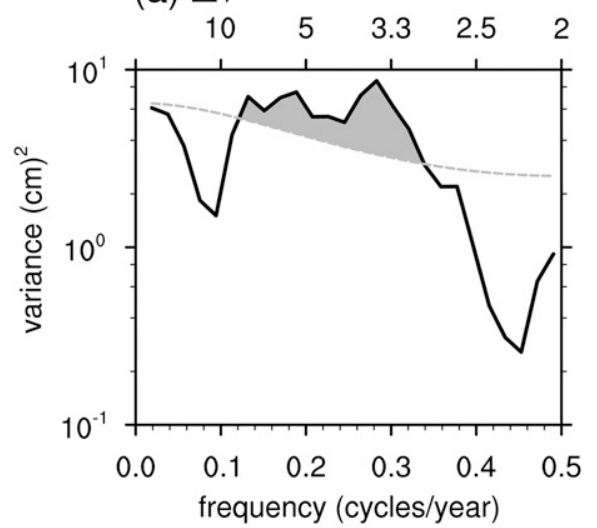

(c) NP

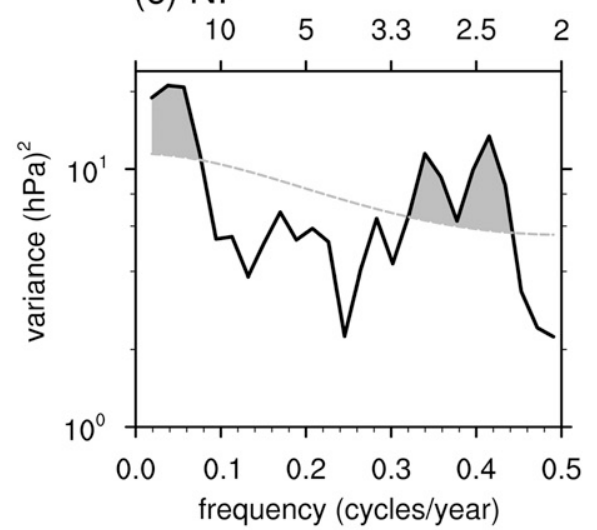

(e) $\underset{10}{N P} \& \frac{\Delta}{5} V$

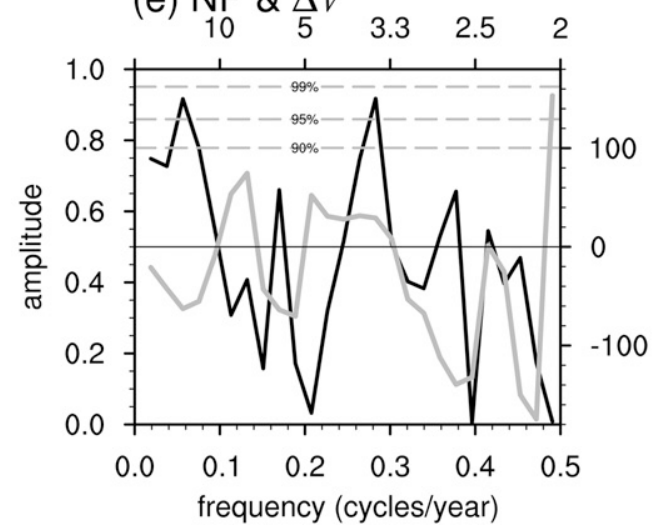

(b) $H$

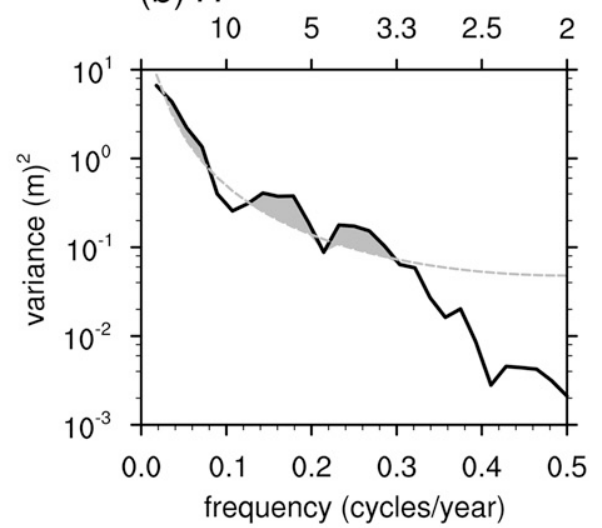

(d) PDO

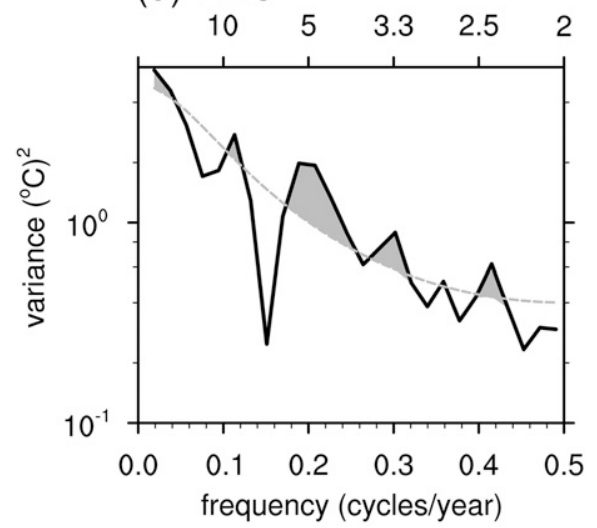

(f) $\mathrm{PDO}_{10} \&_{5} \Delta V_{3.3} \quad 2.5 \quad 2$

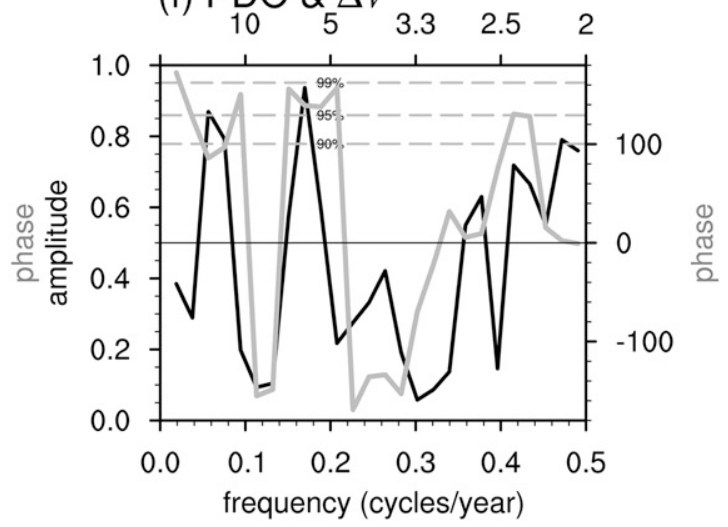

FIG. 3. Power spectra of (a) LQH yearly lake volume changes $\Delta V\left(\mathrm{~cm}^{2}\right)$, (b) yearly water level $H\left(\mathrm{~m}^{2}\right)$, (c) NDJFM NP $\left(\mathrm{hPa}^{2}\right)$, and (d) NDJFM PDO $\left({ }^{\circ} \mathrm{C}^{2}\right)$. Coherence (black line) and phase (gray line) between (e) yearly $\Delta V$ and NDJFM NP and (f) yearly $\Delta V$ and NDJFM PDO index. Gray dashed lines indicate the $90 \%$, $95 \%$, and $99 \%$ confidence levels, respectively, based upon a Student's $t$ test.

empirical orthogonal function (EOF) analysis on the summer 200-hPa geopotential height $\phi$ in the Northern Hemisphere, the first two EOF modes outputted $63.8 \%$ and $15.0 \%$ of the total variance, respectively; this is shown in Fig. 4. Note that all the data here were low-pass filtered with 7 years to capture the interdecadal variability, following Fig. 3 .
The spatial pattern of EOF1 (Fig. 4a) corresponds to a long-term uptrend (Fig. 4d), while the EOF2 spatial pattern outlines the documented Eurasian wave train pattern (Fig. 4b) with an interdecadal variation (Fig. 4e). Similar variations in principle component 1 (PC1) and PC2 are also found in the EOF analysis of yearly $200-\mathrm{hPa}$ circulations, although the spatial pattern is 
(a) EOF1

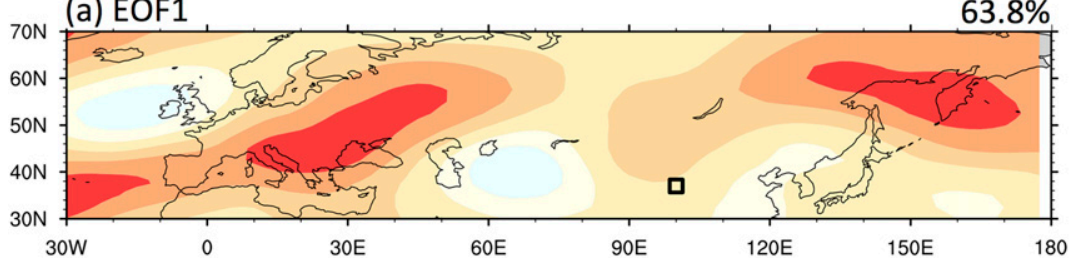

(b) EOF2

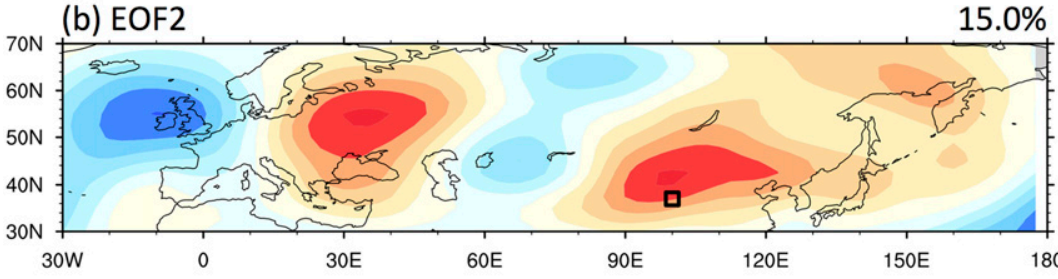

(c) EOF3

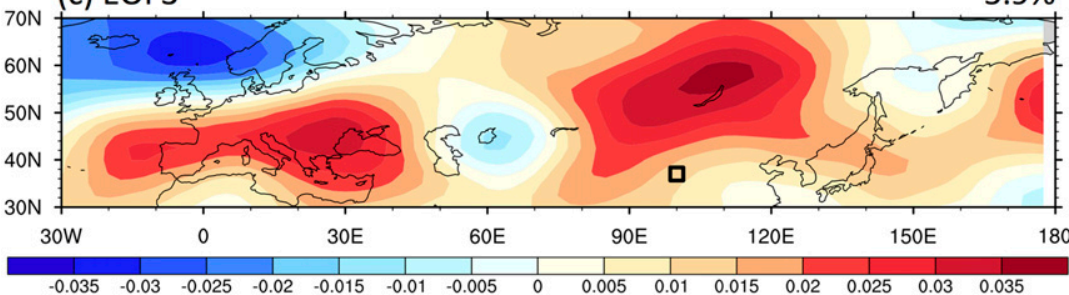

(d) PC1

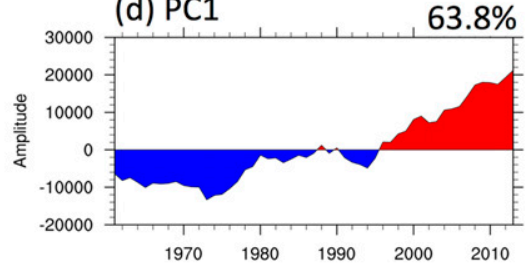

(e) PC2

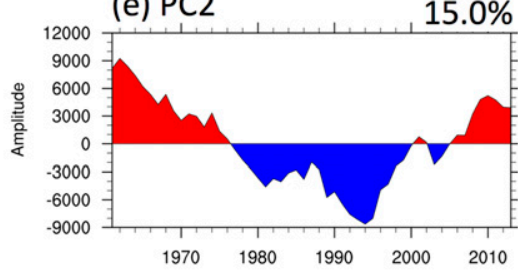

(f) $\mathrm{PC} 3$

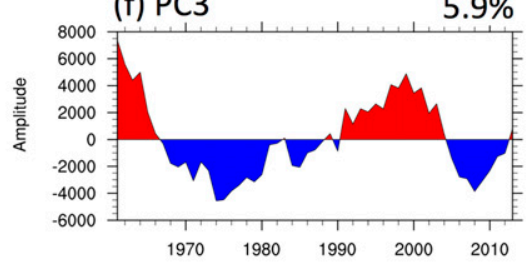

FIG. 4. (a)-(c) EOF spatial pattern of the first three modes of the summer 200-hPa geopotential height $\phi\left(\mathrm{m}^{2} \mathrm{~s}^{-2}\right)(1961-2013)$ over the region of $0^{\circ}-90^{\circ} \mathrm{N}, 180^{\circ}-180^{\circ}$; here, only $30^{\circ}-70^{\circ} \mathrm{N}, 30^{\circ} \mathrm{W}-180^{\circ}$ are plotted to focus on the Eurasian region. The black box indicates the LQH watershed. (d)-(f) PC time series of $\phi$ amplitude $\left(\mathrm{m}^{2} \mathrm{~s}^{-2}\right)$ corresponding to the first three EOF modes.

different from summer (Fig. S2). The correlation of summer PC1 (PC2) and yearly PC1 (PC2) is $0.97(0.89)$, which indicates that the increased trend (i.e., $\mathrm{PC} 1)$ and interdecadal variability (i.e., PC2) over the LQH watershed, is not only dominant during the summer, but also throughout the year. Based upon EOF2's summer spatial pattern, this mode appears to depict the Eurasian wave train that has been found to modulate the South Asian and East Asian climate (Chen and Huang 2012; Ding and Wang 2007).

Since $\nabla \cdot \mathbf{Q}$ represents the atmospheric circulation changes in the water vapor budget equation, the connection between summer $\nabla \cdot \mathbf{Q}$ over the LQH watershed and 200-hPa large-scale circulations was further examined through the one-point linear regression map, with low-pass-filtered data. We flipped $\nabla \cdot \mathbf{Q}$ (i.e., $-\nabla \cdot \mathbf{Q}$ ) to more intuitively link it with precipitation (i.e., "positive" refers to water vapor flux convergence favoring precipitation). The linear regression pattern of the circulation with $-\nabla \cdot \mathbf{Q}$ (Fig. 5a) is similar, with EOF2 supported by a pattern correlation of 0.86 calculated within the domain $30^{\circ}-70^{\circ} \mathrm{N}, 30^{\circ} \mathrm{W}-180^{\circ}$. The depicted teleconnection echoes the Eurasian wave train that originates from the northeast Atlantic and propagates zonally along the Asian jet stream (Enomoto et al. 2003); this Eurasian wave train exhibits three pronounced centers over central Europe, west Asia, and middle Asia. A further analysis of the $200-\mathrm{hPa}$ WAF shows that the teleconnection pattern is accompanied by increased eastward fluxes of Rossby wave activity along the Asian jet stream "waveguide" from the west. The linear regressions of PC2, NP, and PDO (flipped, - PDO) with 200-hPa $\phi$ are also shown in Figs. 5b-d; these are strikingly similar to the $-\nabla \cdot \mathbf{Q}$ regression patterns. The pattern correlations of $200-\mathrm{hPa} \phi$ in Fig. 5a with Figs. 5b-d are $0.90,0.86$, and 0.90 , respectively (calculated within $30^{\circ}-70^{\circ} \mathrm{N}, 30^{\circ} \mathrm{W}-180^{\circ}$ ).

The results presented so far suggest that the variation in summer $-\nabla \cdot \mathbf{Q}$ is highly correlated with $\mathrm{PC} 2$ and NDJFM NP and -PDO, respectively. In other words, the dominant interdecadal oceanic-atmospheric variations of cold season NP and PDO can produce detectable impacts on the LQH watershed through atmospheric teleconnections in the form of short Rossby waves along the jet stream (not unlike the Eurasian wave train or EOF2 as revealed in Fig. 4b). Such interdecadal teleconnection processes appear to have persisted for multiple years across seasons and, in turn, modulated the hydrological cycle of the $\mathrm{LQH}$ watershed.

The atmospheric processes affecting the water vapor convergence over the LQH watershed were further illustrated by the latitude-pressure cross sections of 
(a) WAF ( $-\nabla . \mathbf{Q}$ regressed with $200-\mathrm{hPa} \phi)$

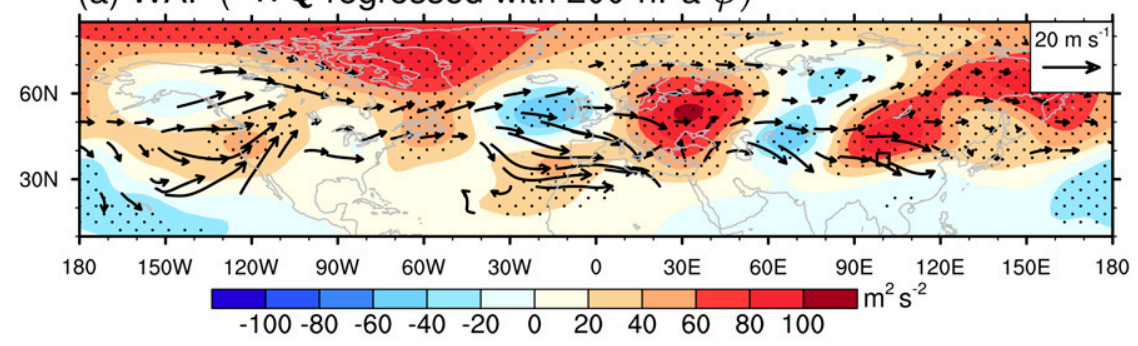

(b) WAF (PC2 regressed with $200-\mathrm{hPa} \phi)$

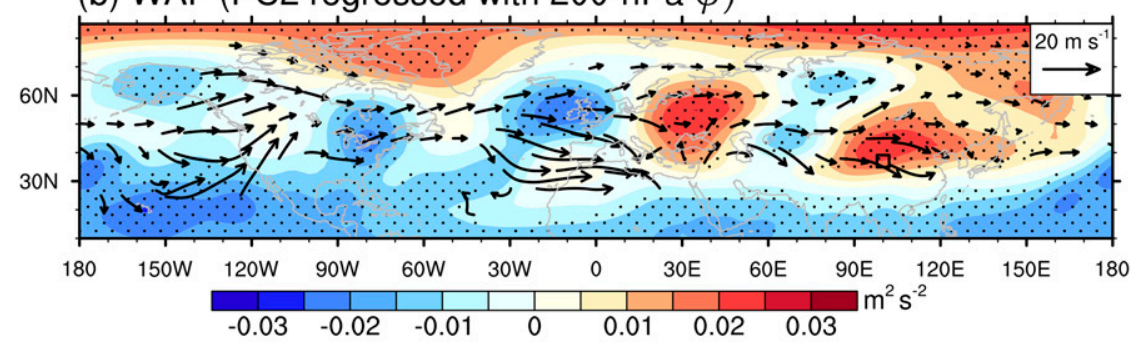

(c) WAF (NP regressed with $200-\mathrm{hPa} \phi$ )

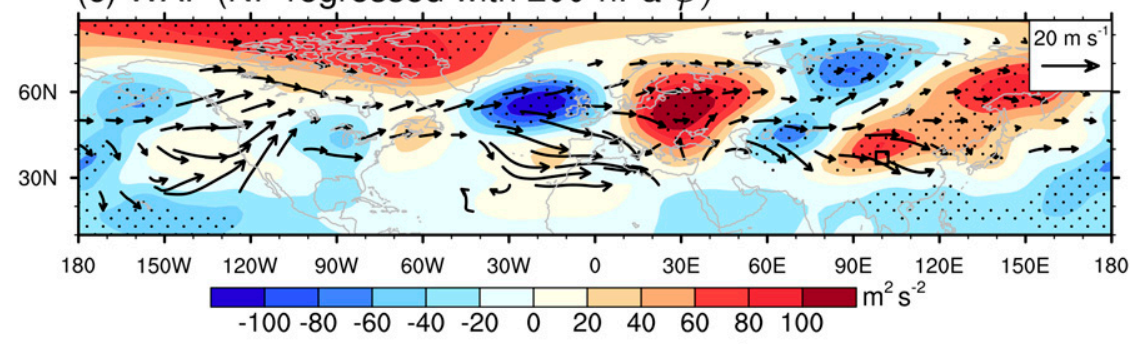

(d) WAF (-PDO regressed with $200-\mathrm{hPa} \phi)$

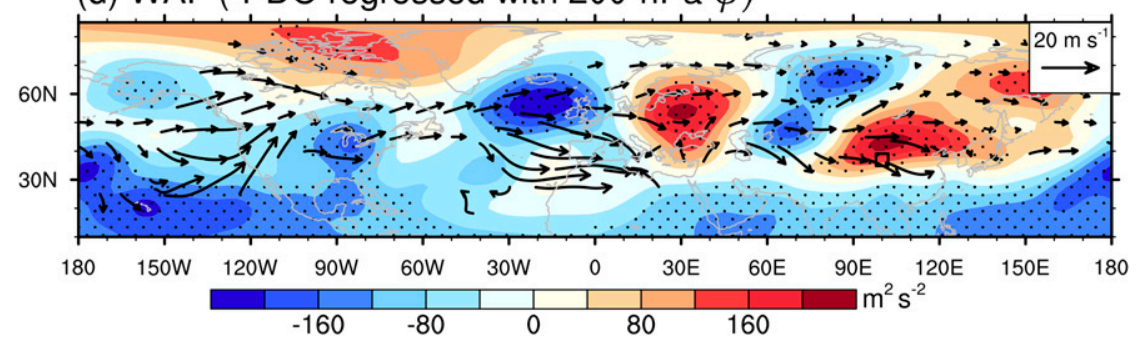

FIG. 5. Regressions (shaded) of $200-\mathrm{hPa} \phi\left(\mathrm{m}^{2} \mathrm{~s}^{-2}\right)$ with (a) summer $-\nabla \cdot \mathbf{Q}$ anomalies (cm month $\left.{ }^{-1}\right)$, (b) PC2 of summer 200-hPa $\phi\left(\mathrm{m}^{2} \mathrm{~s}^{-2}\right)$ as in Fig. 4, (c) NDJFM NP anomalies $(\mathrm{hPa})$, and (d) NDJFM PDO anomalies (flipped, $\left.-\mathrm{PDO} ;{ }^{\circ} \mathrm{C}\right)$. The WAF $\left(\mathrm{m}^{2} \mathrm{~s}^{-2}\right)$ vectors are the climatology at $200-\mathrm{hPa}$; the black box indicates the $\mathrm{LQH}$ watershed, and black dots indicate the $95 \%$ confidence level based upon a Student's $t$ test.

summer meridional wind, vertical velocity, $\phi$, and potential temperature $\theta$ regressed with $-\nabla \cdot \mathbf{Q}$ across the $98.5^{\circ}-101^{\circ} \mathrm{E}$ domain, with low-pass-filtered data. Figure 6a shows a high pressure anomaly extending from the surface to $100 \mathrm{hPa}$ overhead and north of the LQH watershed, associated with upward motion. The high pressure anomaly suggests that the increasing trend of $-\nabla \cdot \mathbf{Q}$ since the mid-1980s and associated upward motion is accompanied by heating in the middle-toupper troposphere, as is shown in Fig. $6 \mathrm{~b}$ by the positive $\theta$ anomaly throughout $200 \mathrm{hPa}$. The fact that positive $\theta$ is centered around $250 \mathrm{hPa}$ indicates that heating does not come from the surface, so the process where the surface heating of the Tibetan Plateau induces the tropospheric heating anomalies is unlikely. Thus, possible sources of the high pressure center over LQH should come from 1) temperature advection within the Eurasian wave train along the jet stream at the upper troposphere ( $\mathrm{Lin}$ and $\mathrm{Lu} 2005$ ) and 2) summertime convection that heats the upper troposphere with the 

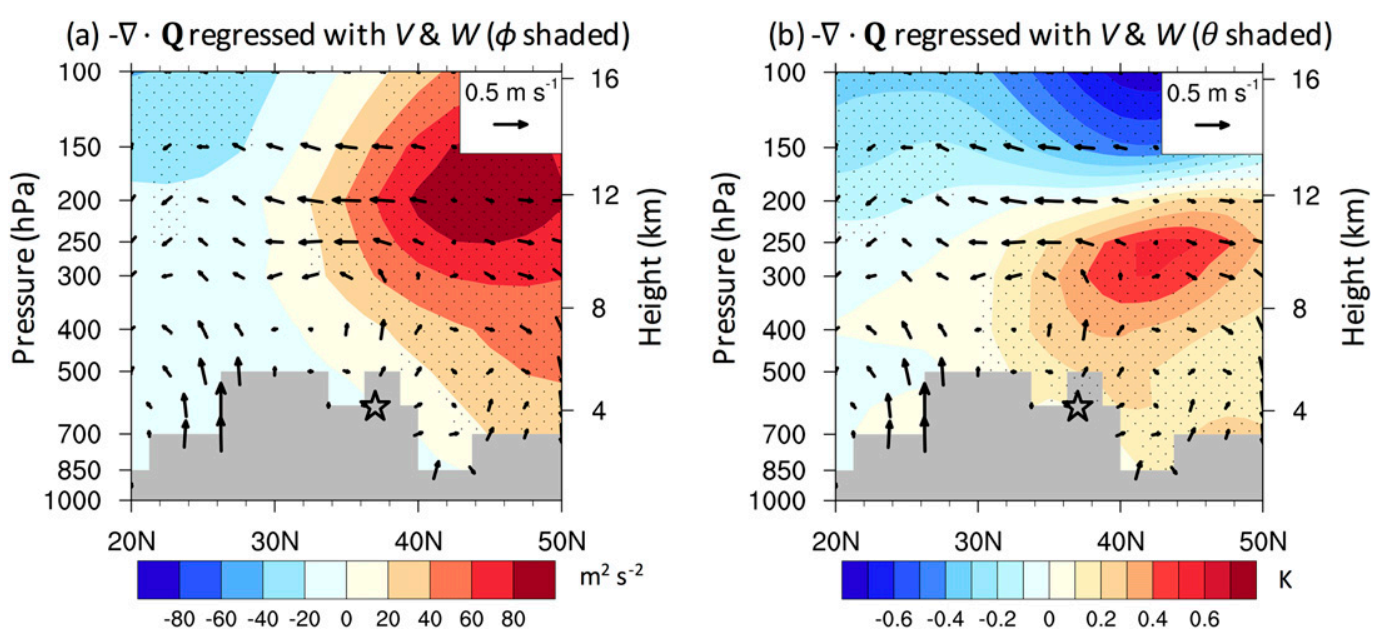

FIG. 6. (a) Regressions of summer LQH $-\nabla \cdot \mathbf{Q}$ anomalies $\left(\mathrm{cm}\right.$ month ${ }^{-1}$ ) to $\phi$ (shaded; $\mathrm{m}^{2} \mathrm{~s}^{-2}$ ) for $v$ and $w\left(\mathrm{~m} \mathrm{~s}^{-1}\right)$. (b) As in (a), but for potential temperature $\theta$ (shaded; $\mathrm{K}$ ); $w$ is magnified by 100 times. The black star indicates the LQH watershed, and black dots indicate the $95 \%$ confidence level based upon a Student's $t$ test.

release of latent heat (similar to what is observed in any summer monsoon regime).

It is important to examine how the aforementioned different modes (i.e., NP, PDO, PC2) interact with each other and with $-\nabla \cdot \mathbf{Q}$ of the LQH watershed, since these climate modes do not necessarily correlate with each other. Using the 7-yr low-pass-filtered data, we produced a scatterplot of PC2 (indicating the Eurasian wave train) with NP (Fig. 7a) and - PDO (Fig. 7b), respectively. The PC2's correlation coefficients over the entire length of data are 0.54 with NP (marginally significant) and 0.74 with - PDO, suggesting that the latter may be a more relevant "forcing" to the teleconnection pattern. By overlapping the magnitude of $-\nabla \cdot \mathbf{Q}$ as indicated by varying size of the circles, two groups emerged; that is, the magnitude of $-\nabla \cdot \mathbf{Q}$ appears to be sorted in ascending order as well as corresponding NP and - PDO. By designating opposing colors for the top $40 \%$ of the data (i.e., $|\nabla \cdot \mathbf{Q}|>1.73 \mathrm{~cm} \mathrm{month}^{-1}$; red for convergence and blue for divergence), the two groups alone led to a distinctively higher correlation, reaching 0.94 with NP and 0.93 with - PDO. This result suggests that the water vapor flux variations over the LHQ watershed are modulated by the Eurasian wave train (PC2), and this modulation is enhanced when the wave train coincides with a constructive NP and/or PDO phasing. During destructive phasing between PC2 and NP/PDO, the teleconnection effect on the $\mathrm{LQH}$ watershed diminishes.

To further quantify the effects of natural variability such as NP and PDO from that of possible anthropogenic sources, we conducted a multiple linear regression method applied to yearly $-\nabla \cdot \mathbf{Q}$ to "regress out" or remove the effects of PC2, NP, and -PDO (Fosu et al. 2016), using a 7-yr low-pass filter. Note here that the intercorrelations between these three climate modes were removed prior to being applied to the $-\nabla \cdot \mathbf{Q}$ data. As shown in the $-\nabla \cdot \mathbf{Q}$ time series (Fig. 8a), the residual $-\nabla \cdot \mathbf{Q}$ encompasses mostly an increasing trend, as the convergence/divergence of atmospheric moisture introduced by constructive/destructive phasing are removed. This residual increase in $-\nabla \cdot \mathbf{Q}$ explains the increasing lake volume observed in the recent decade. The present result suggests that the marked interdecadal variability revealed from the hydrological cycle of the LQH watershed (cf. Fig. 3) originates mostly from the Pacific climate variations in terms of NP and PDO. However, the 2005-15 decrease in $-\nabla \cdot \mathbf{Q}$ occurs with a shorter time scale compared with the interdecadal trend, suggesting other interannual variations not accounted for by NP, PDO, and the climate trend.

\section{c. Attribution implication from CMIP5}

Recall in the introduction that previous studies have debated about the effect of global warming on the LQH water level variations ( $\mathrm{Li}$ et al. 2005, 2007; Xu et al. 2007). The empirical analysis in Fig. 8 suggests that the effect of anthropogenic warming may be an enhancement of the atmospheric water vapor and resultant precipitation, which would translate to increased water levels of LQH. Currently, the only available tool that can test this process is the CMIP5 historical single-forcing experiment. Figure 9 shows that most external forcings (NAT, GHG, AERO, and ALL) produced increased precipitation in the LQH watershed after 1980, which is consistent with the observation. However, the GHG forcing resulted in the strongest and most persistent 

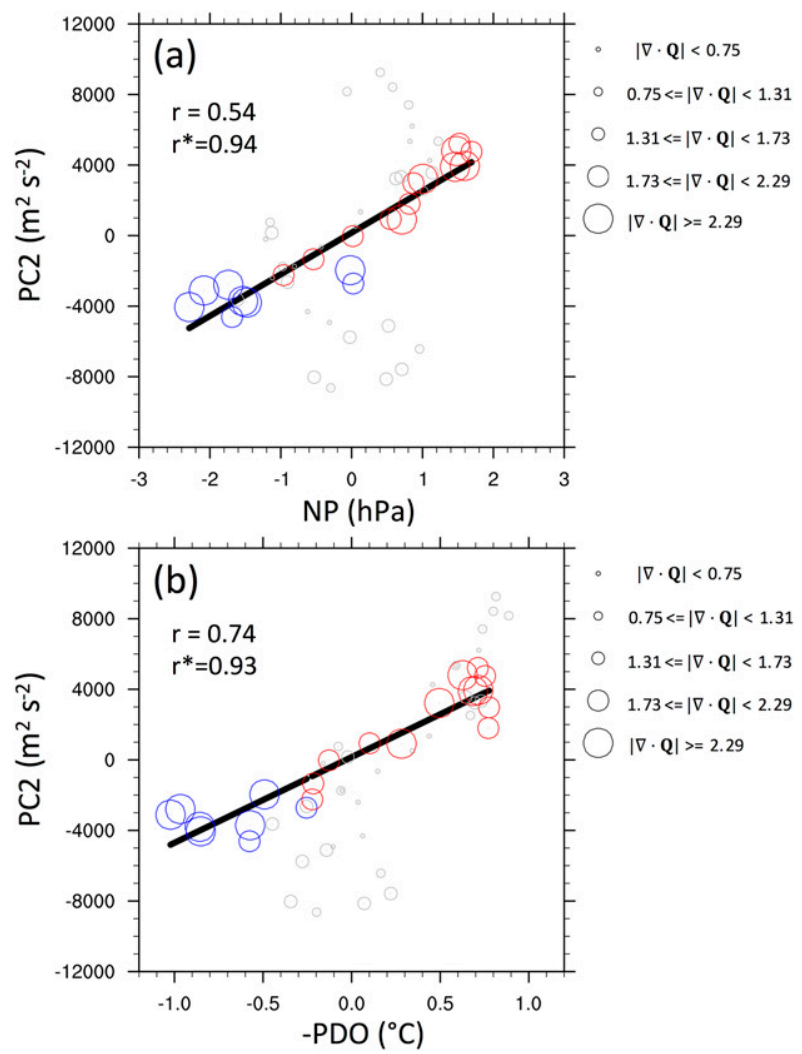

FIG. 7. (a) Scatterplot between PC2 of summer 200-hPa $\phi$ anomalies $\left(\mathrm{m}^{2} \mathrm{~s}^{-2}\right)$ in Fig. 4 and NDJFM NP anomalies (hPa); (b) scatterplot between PC2 of summer $200-\mathrm{hPa} \phi$ anomalies $\left(\mathrm{m}^{2} \mathrm{~s}^{-2}\right)$ in Fig. 4 and NDJFM - PDO anomalies $\left({ }^{\circ} \mathrm{C}\right)$. The size of the circles indicates the magnitude of yearly $-\nabla \cdot \mathbf{Q}$ anomalies $\left(\mathrm{cm} \mathrm{month}^{-1}\right.$ ); colored circles indicate $|\nabla \cdot \mathbf{Q}|>1.73 \mathrm{~cm} \mathrm{month}^{-1}$, where blue (red) indicates negative (positive) values. Variables $r^{*}$ and $r$ indicate correlation with and without the restriction of $|\nabla \cdot \mathbf{Q}|>1.73 \mathrm{~cm} \mathrm{month}^{-1}$, respectively.

trend, while the NAT forcing produced the predominantly interdecadal and weak trend. Therefore, it is likely that the warming atmosphere has led to increased precipitation in response to the increased atmospheric water vapor content (Rangwala et al. 2009; Wentz et al. 2007). Indeed, past research reported that GHG-induced warming can induce Pacific SST gradient changes, thereby affecting the water budget of the monsoon system while producing more precipitation over East Asia (Dwyer et al. 2014; Liu et al. 2013; Xin et al. 2013). However, the increased precipitation produced by the AERO forcing is puzzling and requires further analysis.

\section{Discussion and conclusions}

The interdecadal variations characterizing the LQH water levels were analyzed in terms of the water budget and meteorological diagnostics from 1961 to 2013. The
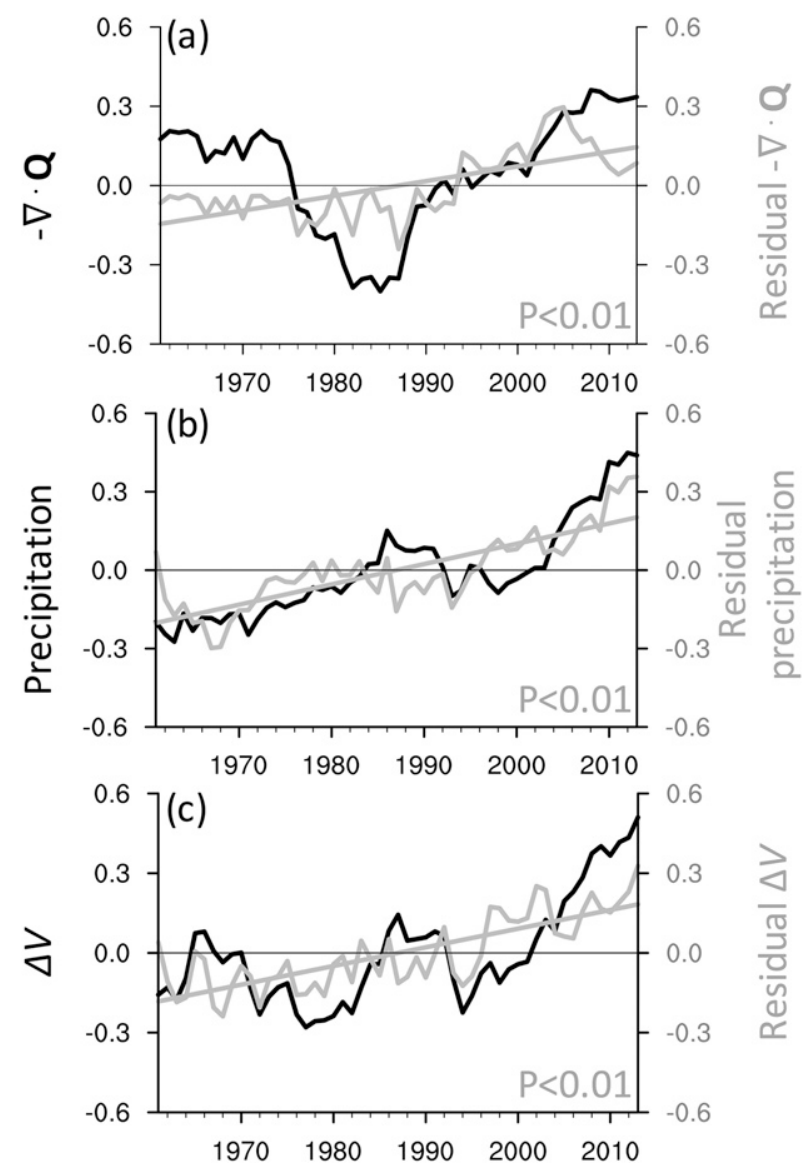

FIG. 8. Yearly (a) $-\nabla \cdot \mathbf{Q}$ anomalies, (b) observed precipitation anomalies, and (c) $\Delta V$ anomalies that were linearly regressed out of the impact of summer PC2, NDJDM NP, and NDJFM - PDO, with a 7-yr low-pass filter; the gray line is the trend of the residual $-\nabla \cdot \mathbf{Q}$, observed precipitation, and $\Delta V$ in (a)-(c), respectively. Normalization is conducted by the anomalies divided by the maximum of the anomalies.

results indicate that the cold-season PDO and NP can affect the summertime wave train (PC2) which, in turn, modulates $\nabla \cdot \mathbf{Q}$ and $\Delta V$ over the $\mathrm{LQH}$ watershed. Since the ocean provides the long-term memory for weather and the climate system through its higher heat capacity (Di Lorenzo and Mantua 2016; Hartmann 2015; Kim et al. 2006), this PDO/NP connection to $\mathrm{LQH}$ can be partly explained by ocean memory. Through EOF and regression analyses, it was found that the water vapor sink over the LQH watershed responds to the summer Eurasian wave train. While the wave train itself is an internal variability mode, it is also modulated by the low-frequency variability associated with $\mathrm{NP}$ and PDO; this explains the marked spectral coherences in the interdecadal frequency shared among the LQH water volume changes, NP, and PDO. Statistical removal of these natural variability modes (NP, PDO, and the 


\section{(a)Observation}

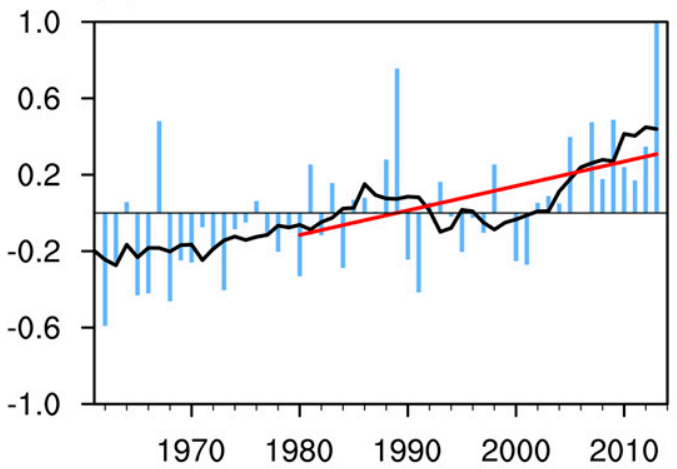

(b)GHG

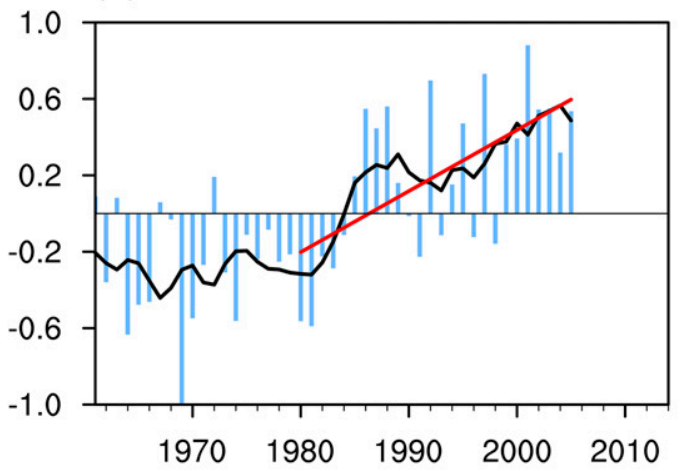

(c)AERO

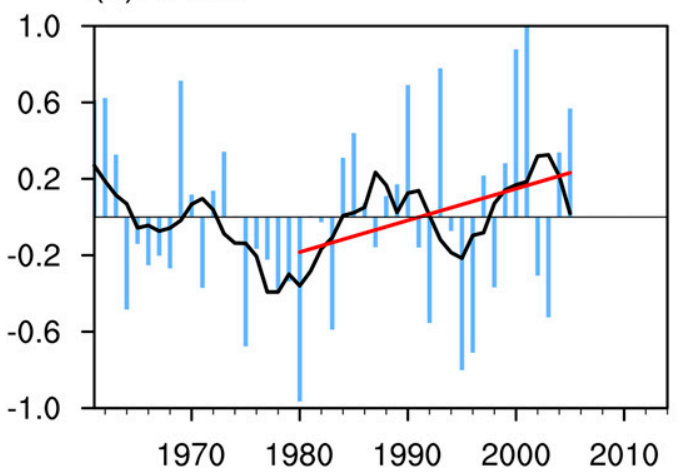

(d)NAT

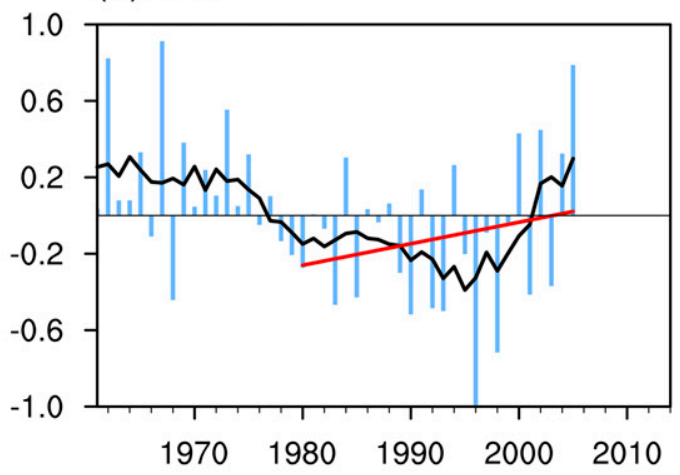

(e)ALL

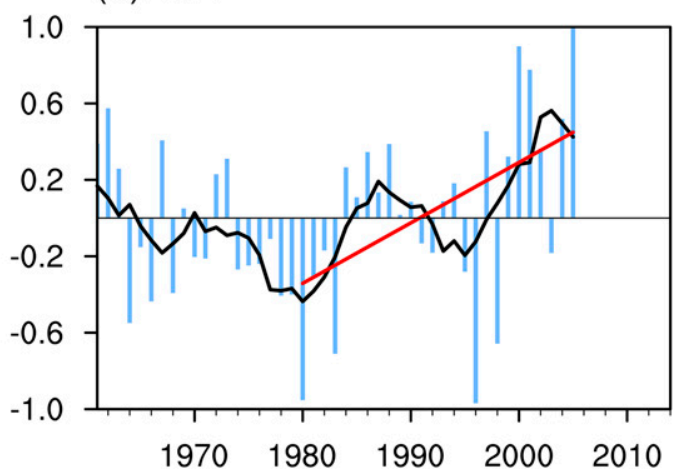

FIG. 9. Comparison of (a) observed precipitation to (b) GHG, (c) AERO, (d) NAT, and (e) ALL CMIP5 simulations; the black line is the 7-yr low-pass filtered data, and the red line is the post-1980 linear trend. Normalization is conducted by the anomalies divided by the maximum of the anomalies.

Eurasian wave train) led to the residual variability manifesting as gradual uptrends in the hydrological variables (water volume, $\nabla \cdot \mathbf{Q}$, and precipitation). Attribution analysis using the CMIP5 single-forcing experiments suggested that the GHG-induced warming has the most pronounced influence on the increase in LQH precipitation, while anthropogenic aerosols may have a contribution as well.

As a terminal lake, it is possible that sedimentation could contribute to LQH's water level increase as well. A recent study by Li et al. (2016) suggests that sediments in LQH appear to increase by less than $10^{-3} \mathrm{~cm} \mathrm{yr}^{-1}$. Compared to the reported lake level changes (from $10^{-1}$ to $10 \mathrm{~cm} \mathrm{yr}^{-1}$; Fig. 1), the sedimentation process is a very small fraction and can be ignored for the analysis period of this study. Furthermore, since the water budget equation in Eq. (4) does not separate soil moisture and groundwater, it may cause uncertainty starting in Eq. (3). This bias in the water budget was evaluated using a smaller domain (focused on LQH rather than its watershed; not shown). The results showed a negligible difference between the LQH watershed and LQH, 
implying that Eq. (4) did approximate a water balance without the consideration of separating soil moisture and groundwater, at least on the watershed scale.

Caution should be exercised when interpreting these results derived from large-scale assimilated and simulation data. First, winter NP and PDO are key factors modulating LQH water level changes that matter more than in summer. As shown in Fig. S3, regression of summer NP (flipped, $-\mathrm{NP}$ ) with $-\nabla \cdot \mathbf{Q}$ is very weak over the $\mathrm{LQH}$ watershed but rather strong from summer - PDO over the LQH watershed. Second, local hydrological processes associated with the LQH water level changes were not included in the analysis because of the lack of credible data, and this can introduce biases into the water budget. Regardless, the results presented in this study suggest that proper monitoring of the NP and PDO status, as well as their interaction (phasing conditions) with the summer Eurasian wave train, may assist in the projection of the LQH water level for the near future. Further modeling work using regional climate and hydrological models to explore the effect with or without the interdecadal variance of NP and PDO, the differentiation of surface and subsurface water flows, and an increased precipitation network throughout the watershed will help us understand the mechanisms of the climate connection of LQH.

Acknowledgments. This research was supported by the National Natural Science Foundation of China (41405020, 91637107, 91437102, 91537214, 91537104, 41675015, 41605011, 41405015), the Science and Technology Service Network Initiative of CAREERI (651671001), and the Research Program of the Sino-German Center GZ1259. S.-Y. Simon Wang was supported by U.S. Department of Energy Grant DE-SC0016605 and U.S. Bureau of Reclamation Grant R13AC80039, as well as the Utah Agricultural Experiment Station.

\section{REFERENCES}

Che, T., X. Li, and R. Jin, 2009: Monitoring the frozen duration of Qinghai Lake using satellite passive microwave remote sensing low frequency data. Chin. Sci. Bull., 54, 2294-2299, doi:10.1007/s11434-009-0044-3.

Chen, G., and R. Huang, 2012: Excitation mechanisms of the teleconnection patterns affecting the July precipitation in northwest China. J. Climate, 25, 7834-7851, doi:10.1175/ JCLI-D-11-00684.1.

Cochran, W. T., and Coauthors, 1967: What is the fast Fourier transform? Proc. IEEE, 55, 1664-1674, doi:10.1109/ PROC.1967.5957.

Crétaux, J.-F., and Coauthors, 2011: SOLS: A lake database to monitor in the Near Real Time water level and storage variations from remote sensing data. Adv. Space Res., 47, 1497-1507, doi:10.1016/j.asr.2011.01.004.

Daniell, P. J., 1946: Discussion on the symposium on autocorrelation in time series. J. Roy. Stat. Soc., 8 (Suppl.), 88-90.
Dee, D., and Coauthors, 2011: The ERA-Interim reanalysis: Configuration and performance of the data assimilation system. Quart. J. Roy. Meteor. Soc., 137, 553-597, doi:10.1002/qj.828.

Di Lorenzo, E., and N. Mantua, 2016: Multi-year persistence of the 2014/15 North Pacific marine heatwave. Nat. Climate Change, 6, 1042-1047, doi:10.1038/nclimate3082.

Ding, Q., and B. Wang, 2005: Circumglobal teleconnection in the Northern Hemisphere summer. J. Climate, 18, 3483-3505, doi:10.1175/JCLI3473.1.

— and - 2007: Intraseasonal teleconnection between the summer Eurasian wave train and the Indian monsoon J. Climate, 20, 3751-3767, doi:10.1175/JCLI4221.1.

Dwyer, J. G., M. Biasutti, and A. H. Sobel, 2014: The effect of greenhouse gas-induced changes in SST on the annual cycle of zonal mean tropical precipitation. J. Climate, 27, 4544-4565, doi:10.1175/JCLI-D-13-00216.1.

Enomoto, T., B. J. Hoskins, and Y. Matsuda, 2003: The formation mechanism of the Bonin high in August. Quart. J. Roy. Meteor Soc., 129, 157-178, doi:10.1256/qj.01.211.

Fosu, B. O., S.-Y. Simon Wang, and J.-H. Yoon, 2016: The 2014/15 snowpack drought in Washington State and its climate forcing [in "Explaining Extreme Events of 2015 from a Climate Perspective"]. Bull. Amer. Meteor. Soc., 97 (12), S19-S24, doi:10.1175/BAMS-ExplainingExtremeEvents2015.1.

Hartmann, D. L., 2015: Pacific sea surface temperature and the winter of 2014. Geophys. Res. Lett., 42, 1894-1902, doi:10.1002/2015GL063083.

Hawkins, E., and R. Sutton, 2009: The potential to narrow uncertainty in regional climate predictions. Bull. Amer. Meteor. Soc., 90, 1095-1107, doi:10.1175/2009BAMS2607.1.

Hu, W., A. Duan, Y. Li, and B. He, 2016: The intraseasonal oscillation of eastern Tibetan Plateau precipitation in response to the summer Eurasian wave train. J. Climate, 29, 7215-7230, doi:10.1175/JCLI-D-15-0620.1.

Jin, Z., C.-F. You, Y. Wang, and Y. Shi, 2010: Hydrological and solute budgets of Lake Qinghai, the largest lake on the Tibetan Plateau. Quat. Int., 218, 151-156, doi:10.1016/ j.quaint.2009.11.024.

Kanamitsu, M., W. Ebisuzaki, J. Woollen, S.-K. Yang, J. Hnilo, M. Fiorino, and G. Potter, 2002: NCEP-DOE AMIP-II Reanalysis (R-2). Bull. Amer. Meteor. Soc., 83, 1631-1643, doi:10.1175/BAMS-83-11-1631.

Kim, T. W., J. B. Valdés, B. Nijssen, and D. Roncayolo, 2006: Quantification of linkages between large-scale climatic patterns and precipitation in the Colorado River Basin. J. Hydrol., 321, 173-186, doi:10.1016/j.jhydrol.2005.07.043.

Kobayashi, S., and Coauthors, 2015: The JRA-55 Reanalysis: General specifications and basic characteristics. J. Meteor. Soc. Japan, 93, 5-48, doi:10.2151/jmsj.2015-001.

Lei, Y., T. Yao, C. Yi, W. Wang, Y. Sheng, J. Li, and D. Joswiak, 2012: Glacier mass loss induced the rapid growth of Linggo Co on the central Tibetan Plateau. J. Glaciol., 58, 177-184, doi:10.3189/2012JoG11J025.

_ - K. Yang, B. Wang, Y. Sheng, B. W. Bird, G. Zhang, and L. Tian, 2014: Response of inland lake dynamics over the Tibetan Plateau to climate change. Climatic Change, 125, 281-290, doi:10.1007/s10584-014-1175-3.

Li, G., H. Dong, W. Hou, S. Wang, H. Jiang, J. Yang, and G. Wu, 2016: Temporal succession of ancient phytoplankton community in Qinghai Lake and implication for paleo-environmental change. Sci. Rep., 6, 19769, doi:10.1038/srep19769.

Li, L., X. D. Zhu, Z. Y. Wang, and Q. C. Wang, 2005: Impacting factors and changing tendency of water level in Qinghai Lake 
in recent 42 years. J. Desert Res., 25, 689-696, doi:10.2166/ nh.2015.237.

Li, X. Y., H. Y. Xu, Y. L. Sun, D. S. Zhang, and Z. P. Yang, 2007: Lake-level change and water balance analysis at Lake Qinghai, west China during recent decades. Water Resour. Manage., 21, 1505-1516, doi:10.1007/s11269-006-9096-1.

Li, Y., J. Liao, H. Guo, Z. Liu, and G. Shen, 2014: Patterns and potential drivers of dramatic changes in Tibetan lakes, 1972-2010. PLoS One, 9, e111890, doi:10.1371/journal.pone.0111890.

Lin, Z., and R. Lu, 2005: Interannual meridional displacement of the East Asian upper-tropospheric jet stream in summer. $A d v$. Atmos. Sci., 22, 199, doi:10.1007/BF02918509.

Liu, J., S. Kang, T. Gong, and A. Lu, 2010: Growth of a highelevation large inland lake, associated with climate change and permafrost degradation in Tibet. Hydrol. Earth Syst. Sci., 14, 481-489, doi:10.5194/hess-14-481-2010.

—, B. Wang, M. A. Cane, S.-Y. Yim, and J.-Y. Lee, 2013: Divergent global precipitation changes induced by natural versus anthropogenic forcing. Nature, 493, 656-659, doi:10.1038/nature11784.

Mantua, N. J., S. R. Hare, Y. Zhang, J. M. Wallace, and R. C. Francis, 1997: A Pacific interdecadal climate oscillation with impacts on salmon production. Bull. Amer. Meteor. Soc., 78, 1069-1079, doi:10.1175/1520-0477(1997)078<1069:APICOW>2.0.CO;2.

Newman, M., and Coauthors, 2016: The Pacific decadal oscillation, revisited. J. Climate, 29, 4399-4427, doi:10.1175/JCLI-D-15-0508.1.

Peixoto, J. P., and A. H. Oort, 1992: Physics of Climate. American Institute of Physics, $520 \mathrm{pp}$.

Qin, B., and Q. Huang, 1998: Evaluation of the climatic change impacts on the inland lake-A case study of Lake Qinghai, China. Climatic Change, 39, 695-714, doi:10.1023/ A:1005319616456.

Qing, B., and Y. Shi, 1992: The hydrological characteristics and the cause of the declining of water level in Qinghai Lake. Acta Geogr. Sin., 47, 267-273, doi:10.11821/xb199203008.

Rangwala, I., J. R. Miller, and M. Xu, 2009: Warming in the Tibetan Plateau: Possible influences of the changes in surface water vapor. Geophys. Res. Lett., 36, L06703, doi:10.1029/ 2009GL037245.

Sha, Y., Z. Shi, X. Liu, and Z. An, 2015: Distinct impacts of the Mongolian and Tibetan Plateaus on the evolution of the East Asian monsoon. J. Geophys. Res. Atmos., 120, 4764-4782, doi:10.1002/2014JD022880.

Shanahan, T. M., J. T. Overpeck, W. E. Sharp, C. A. Scholz, and J. A. Arko, 2007: Simulating the response of a closed-basin lake to recent climate changes in tropical West Africa (Lake Bosumtwi, Ghana). Hydrol. Processes, 21, 1678-1691, doi:10.1002/hyp.6359.

Shi, X., L. Li, Q. Wang, P. Liu, H. Zhang, and Z. Liu, 2005: Climatic change and its influence on water level of Qinghai Lake. Meteor. Sci. Tech., 33, 58-62.

Song, C., B. Huang, and L. Ke, 2013: Modeling and analysis of lake water storage changes on the Tibetan Plateau using multi-mission satellite data. Remote Sens. Environ., 135, 25-35, doi:10.1016/j.rse.2013.03.013.

—, K. Richards, L. Ke, and V. Hien Phan, 2014: Accelerated lake expansion on the Tibetan Plateau in the 2000s: Induced by glacial melting or other processes? Water Resour. Res., 50, 3170-3186, doi:10.1002/2013WR014724.

Takaya, K., and H. Nakamura, 2001: A formulation of a phaseindependent wave-activity flux for stationary and migratory quasigeostrophic eddies on a zonally varying basic flow. J. Atmos. Sci., 58, 608-627, doi:10.1175/1520-0469(2001)058<0608: AFOAPI $>2.0 . \mathrm{CO} ; 2$

Taylor, K. E., R. J. Stouffer, and G. A. Meehl, 2012: An overview of CMIP5 and the experiment design. Bull. Amer. Meteor. Soc., 93, 485-498, doi:10.1175/BAMS-D-11-00094.1.

Trenberth, K. E., and J. W. Hurrell, 1994: Decadal atmosphereocean variations in the Pacific. Climate Dyn., 9, 303-319, doi:10.1007/BF00204745.

Uppala, S. M., and Coauthors, 2005: The ERA-40 Re-analysis. Quart. J. Roy. Meteor. Soc., 131, 2961-3012, doi:10.1256/ qj.04.176.

Wang, S.-Y., R. R. Gillies, J. Jin, and L. E. Hipps, 2010: Coherence between the Great Salt Lake level and the Pacific quasidecadal oscillation. J. Climate, 23, 2161-2177, doi:10.1175/ 2009JCLI2979.1.

Wentz, F. J., L. Ricciardulli, K. Hilburn, and C. Mears, 2007: How much more rain will global warming bring? Science, 317, 233-235, doi:10.1126/science.1140746.

Wu, J., and X. Gao, 2013: A gridded daily observation dataset over China region and comparison with the other datasets. Chin. J. Geophys., 56, 1102-1111, doi:10.6038/cjg20130406.

Xin, X., L. Zhang, J. Zhang, T. Wu, and Y. Fang, 2013: Climate change projections over East Asia with BCC_CSM1.1 climate model under RCP scenarios. J. Meteor. Soc. Japan, 91, 413-429, doi:10.2151/jmsj.2013-401.

$\mathrm{Xu}, \mathrm{H} ., \mathrm{X}$. Li, and Y. Sun, 2007: Climatic change in the Lake Qinghai watershed in recent 47 years. Arid Meteor., 2, 50-54.

Yang, K., H. Wu, J. Qin, C. Lin, W. Tang, and Y. Chen, 2014: Recent climate changes over the Tibetan Plateau and their impacts on energy and water cycle: A review. Global Planet. Change, 112, 79-91, doi:10.1016/j.gloplacha.2013.12.001.

Yao, T., and Coauthors, 2012: Different glacier status with atmospheric circulations in Tibetan Plateau and surroundings. Nat. Climate Change, 2, 663-667, doi:10.1038/nclimate1580.

Zhang, G., H. Xie, S. Kang, D. Yi, and S. F. Ackley, 2011: Monitoring lake level changes on the Tibetan Plateau using ICESat altimetry data (2003-2009). Remote Sens. Environ., 115, 1733-1742, doi:10.1016/j.rse.2011.03.005.

,,- T. Yao, and S. Kang, 2013: Water balance estimates of ten greatest lakes in China using ICESat and Landsat data. Chin. Sci. Bull., 58, 3815-3829, doi:10.1007/s11434-013-5818-y.

_, T. Yao, H. Xie, K. Zhang, and F. Zhu, 2014: Lakes' state and abundance across the Tibetan Plateau. Chin. Sci. Bull., 59, 3010-3021, doi:10.1007/s11434-014-0258-x. 